Article

\title{
Preparation of PVA-Based Hollow Fiber Ion-Exchange Membranes and Their Performance for Donnan Dialysis
}

\author{
Mitsuru Higa ${ }^{1,2, *}$, Yuriko Kakihana ${ }^{1,2}$, Takehiro Sugimoto ${ }^{3}$ and Kakuya Toyota ${ }^{3}$ \\ 1 Graduate School of Sciences and Technology for Innovation, Yamaguchi University, 2-16-1 Tokiwadai, Ube, \\ Yamaguchi 755-8611, Japan; kakihana@yamaguchi-u.ac.jp \\ 2 Blue Energy Center for SGE Technology (BEST), Yamaguchi University, 2-16-1 Tokiwadai, Ube, \\ Yamaguchi 755-8611, Japan \\ 3 Graduate School of Science and Engineering, Yamaguchi University, 2-16-1 Tokiwadai, Ube, \\ Yamaguchi 755-8611, Japan; i051vf@yamaguchi-u.ac.jp (T.S.); g012vf@yamaguchi-u.ac.jp (K.T.) \\ * Correspondence: mhiga@yamaguchi-u.ac.jp; Tel.: +81-836-85-9203
}

Received: 28 November 2018; Accepted: 18 December 2018; Published: 2 January 2019

\begin{abstract}
Hollow fiber type cation-exchange (C-HF) membranes and hollow fiber type anion-exchange (A-HF) membranes were prepared from poly (vinyl alcohol) (PVA)-based copolymer with cation-exchange groups and by blending PVA and polycation, respectively, by a gel fiber spinning method. In order to control the water content of the hollow fiber membranes, the membranes were cross-linked physically by annealing, and then cross-linked chemically by using glutaraldehyde (GA) solutions at various GA concentrations. The outer diameter of C-HF and A-HF membranes were ca. $1000 \mu \mathrm{m}$ and ca. $1500 \mu \mathrm{m}$, respectively, and the thickness of the membranes were ca. $170 \mu \mathrm{m}$ and $290 \mu \mathrm{m}$, respectively. Permeation experiments were carried out in two Donnan dialysis systems, which included mixed $0.1 \mathrm{M} \mathrm{NaCl}$ and $0.1 \mathrm{M} \mathrm{CaCl}_{2} / \mathrm{C}-\mathrm{HF} / 3 \times 10^{-4} \mathrm{M} \mathrm{CaCl}_{2}$ and mixed $0.1 \mathrm{M} \mathrm{NaCl}$ and $0.1 \mathrm{M} \mathrm{NaNO}_{3} / \mathrm{A}-\mathrm{HF} / 3 \times 10^{-4} \mathrm{M} \mathrm{NaNO}_{3}$ to examine ionic perm selectivity of the membranes. In the Donnan dialysis experiments using C-HF membranes, uphill transport of the divalent cations occurred, and, in the case of A-HF membranes, uphill transport of $\mathrm{NO}_{3}{ }^{-}$ions occurred. C-HF and A-HF membranes had about half of the flux in the uphill transported ions and also about half of the selectivity between the uphill transport ions and driven ions in comparison with those of the commercial flat sheet cation-exchange membrane (Neosepta ${ }^{\circledR} \mathrm{CMX}$ ) and anion-exchange membrane (Neosepta ${ }^{\circledR}$ AMX). Yet, IEC of C-HF and A-HF membranes were about one fifth of CMX and less than half of AMX, respectively. Since hollow fiber membrane module will have higher packing density than a flat membrane stack, the hollow fiber type ion-exchange membranes (IEMs) prepared in this study will have a potential application to a Donnan dialysis process.
\end{abstract}

Keywords: ion exchange membranes; poly (vinyl alcohol); hollow fiber; Donnan dialysis

\section{Introduction}

Ion-exchange membranes (IEMs) have been widly used in various industrial fields [1-5]. There are two separation processes using IEMs: electrodialysis (ED) driven by the applied voltage [4,5], and diffusion dialysis driven by the concentration gradient [6,7]. ED processes have been applied to table salt production from seawater in Japan $[1,4,8]$, in the food industry such as demineralization of whey and pretreatment of fruit juice $[9,10]$, and waste water treatment [11]. An example of diffusion dialysis processes are recovery of acids and bases used in metal treatment processes [12]. In a separation process driven by the concentration gradient using IEMs, a Donnan dialysis (DD) utilizes counter diffusion of counter-ions of IEMs through the IEM to achieve removal and concentration of other 
counter-ions [13-15]. Figure 1 shows a DD system where a cation-exhange membrane (CEM) is placed between two chambers. In the system, the electric current, $I$, must be zero. Hence, the following equation is given in the system.

$$
I=F S \sum z_{i} J_{i}=0
$$

where $F$ is the Faraday's constant. Hence, in the DD system, the following equation should be given from Equation (1).

$$
J_{\mathrm{Md}}+z_{u} J_{\mathrm{Mu}}-J_{\mathrm{A}}=0
$$

where $J_{\mathrm{Md}}, J_{\mathrm{Mu}}$, and $J_{\mathrm{A}}$ are flux of $\mathrm{M}_{\mathrm{d}}{ }^{+}$ions, $\mathrm{M}_{\mathrm{u}}{ }^{\mathrm{z+}}$ ions, and $\mathrm{A}^{-}$ions, respectively.

Under an assumption that the CEM in the system has perfect permselectivity for cations, the flux of anions becomes zero. Hence, the formula below is true.

$$
J_{\mathrm{Md}}=-z_{u} J_{\mathrm{Mu}}
$$

Equation (3) indicates that $\mathrm{M}_{\mathrm{u}}{ }^{\mathrm{z+}}$ ions are transported against their concentration gradient from side II to side I, which is called as uphill transport, driven by the diffusion of the driving cations known as $\mathrm{M}_{\mathrm{d}}{ }^{+}$ions. In this study, the selectivity coefficient, $\alpha$, is defined from $J_{\mathrm{Md}}$ and $J_{\mathrm{Mu}}$ in terms of the following equation.

$$
\alpha=-\frac{z_{u} J_{\mathrm{Mu}}}{J_{\mathrm{Md}}}
$$

If the system has ideal selectivity for cations, in other words, the flux of co-ions is equal to zero, $\alpha$ turns into unity.

DD processes can be applied for the removal, recovery, separation, and concentrations of heavy metal ions [14], and the removal of harmful anions such as nitrate ions and fluoride ions from water [15].

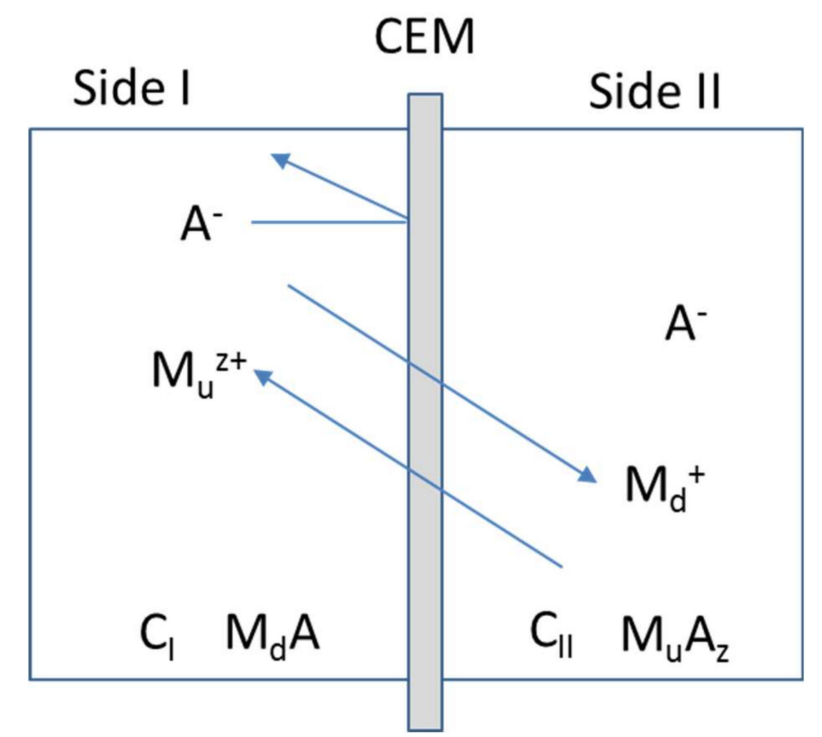

Figure 1. A schematic diagram of an example of Donnan dialylsis system with a cation-exchange membrane. In this case, side I and II chambers contain $\mathrm{M}_{\mathrm{d}} \mathrm{A}$ as the driving electrolyte at an initial concentration of $C_{I}$, and $M_{u} A_{z}$ at an initial concentration of $C_{I I}$ where the driving cations are the monovalnet ion, $\mathrm{M}_{\mathrm{d}}{ }^{+}$, and the uphill transported ions are $\mathrm{M}_{\mathrm{u}}{ }^{\mathrm{z}}$ ions. The system has common anions as $\mathrm{A}^{-}$ions generally. In a DD system, $\mathrm{C}_{\mathrm{I}}$ is higher than $\mathrm{C}_{\mathrm{II}}$.

The DD process has been performed using a stack with a plate-and-frame configuration $[1,3,7]$. This configuration requires expensive flat sheet ion-exchange membranes and expensive spacers with gaskets. The process is not applied in industry mainly because of its slow kinetics [15]. The membrane module for hollow fiber type ion-exchange membranes had higher packing density 
(high membrane surface area in a unit volume) than the plate-and-frame stack. In addition, it does not need spacers [16]. Hence, hollow fiber membranes have been widely used for various fields such as medical use for hemodialysis as well as water treatment for purification of wastewater and seawater desalination [17-21]. Therefore, recently, there have been many studies on the preparation of hollow fiber type ion-exchange membranes [15,22-24]. Saito et al. prepared cation-exchange porous hollow fiber membranes by a radiation-induced co-grafting method [22]. Kiyono et al. prepared mixed matrix microporous hollow fiber membranes by a wet spinning technique [16].

On the other hand, recently, poly (vinyl alcohol) (PVA)-based ion-exchange membranes have been studied [25-28]. Since PVA is a semi-crystalline polymer, heat-treatment above the glass-transition temperature [29,30] increases the crystallinity of the polymer, which acts as a physical network [31]. Moreover, PVA is a polyhydroxy polymer. Hence, PVA chains can be chemically crosslinked using crosslinking agents such as glutaraldehyde (GA) [32]. Therefore, the water content of the membrane, which plays an important role in the ionic perm selectivity and mechanical strength, can be easily controlled by annealing an as-cast membrane and/or cross-linking it by using cross-linking agents.

In this study, we prepared hollow fiber type cation-exchange (C-HF) membranes and hollow fiber type anion-exchange (A-HF) membranes from a PVA-based copolymer with cation-exchange groups and by blending PVA and polycations, respectively, by the gel spinning method. Afterward, the basic property of the HF membranes was investigated. Donnan dialysis experiments were performed with the systems of mixed $\mathrm{NaCl}$ and $\mathrm{CaCl}_{2} / \mathrm{C}-\mathrm{HF} / \mathrm{CaCl}_{2}$ where $\mathrm{Ca}^{2+}$ ions were model heavy metal ions, and mixed $\mathrm{NaCl}$ and $\mathrm{NaNO}_{3} / \mathrm{A}-\mathrm{HF} / \mathrm{M} \mathrm{NaNO}$ were used to examine the ionic selectivity of the prepared hollow fiber type IEMs.

\section{Materials and Methods}

\subsection{Materials}

Poly(vinyl alcohol) (PVA, average $M_{\mathrm{w}}=85,000-124,000 \mathrm{~g} \cdot \mathrm{mol}^{-1}$, degree of hydrolysis $=99 \%$ ) was purchased from Aldrich (Milwaukee, WI, USA), poly (diallyl dimethyl ammonium chloride) (PDADMAC) was purchased from Sigma-Aldrich Co. LLC. (St. Louis, MO, USA) and poly(vinyl alcohol-co-2-acrylamido-2-methyl propane sulfonic acid) (AP-2, average $M_{\mathrm{W}}=70,000 \mathrm{~g} \cdot \mathrm{mol}^{-1}$, degree of hydrolysis $=99.5 \%$ ) was obtained from KURARAY Co., Ltd. (Tokyo, Japan). AP-2 is a modified PVA that contains $2 \mathrm{~mol} \%$ of 2-acrylamido-2-methylpropane sulfonic acid groups as a copolymer, and, hence, provides cation-exchange sites. Commercial IEMs, Neosepta ${ }^{\circledR}$ CMX and AMX were obtained from the ASTOM Corporation (Tokyo, Japan). Unless otherwise specified, special solvents and reagents purchased from Sigma-Aldrich Japan Co., Ltd. (Tokyo, Japan), Nacalai Tesque, Inc. (Kyoto, Japan) and Wako Pure Chemical Industries, Ltd. (Tokyo, Japan) were used as they were. Figure 2 shows the Chemical structure of PVA, AP-2, and PDADMAC polymers used in this study.

(a)<smiles>CCCC(C)O</smiles>
PVA (b)<smiles>CC(C)(C)CC(O)CC(CC(=O)O)C(=O)NC(C)(C)C</smiles>

(c)<smiles>CCCCCC1C[N+](C)(Cl)CC1CCC</smiles>

PDADMAC

AP-2

Figure 2. Chemical structure of (a) PVA, (b) AP-2, and (c) PDADMAC polymers used in this study. 


\subsection{Preparation of Hollow Fiber Type Ion-Exchange Membranes}

\subsubsection{Preparation of Spinning Solution}

For preparing C-HF membranes, $10 \mathrm{~g}$ of AP-2, $0.4 \mathrm{~g}$ of boric acid, $0.2 \mathrm{~g}$ of acetic acid, and $45.5 \mathrm{~mL}$ of deionized water were mixed to prepare a solution of AP-2:deionized water $=18: 82(\mathrm{w} / \mathrm{w})$. For preparing A-HF membranes, $8 \mathrm{~g}$ of PVA-124, $10 \mathrm{~g}$ of $20 \mathrm{wt} . \%$ PDADMAC aqueous solution, $0.32 \mathrm{~g}$ of boric acid, $0.16 \mathrm{~mL}$ of acetic acid, and $42 \mathrm{~mL}$ of deionized water were mixed to prepare a solution of (PVA/PDADMAC): deionized water $=19: 81(\mathrm{w} / \mathrm{w})$. The theoretical ion-exchange capacity calculated from the molar percent of the charged groups in AP-2, and the mixture ratio of PVA and PDADMAC were 0.42 for C-HF and 1.25 (meq/g) for A-HF membranes, respectively. These solutions were heated in a water bath at $100{ }^{\circ} \mathrm{C}$ for $5 \mathrm{~h}$ to obtain spinning solutions.

\subsubsection{Spinning of Hollow Fiber Ion-Exchange Membranes}

Spinning of hollow fiber type IEMs was performed in the same method as described elsewhere [33] by using the spinning apparatus shown in Figure 3. The AP-2 solution and the PVA/PDADMAC solution were put in the dope solution tank for preparing C-HF and A-HF membranes, respectively, and the bore fluid was put in the bore fluid tank. The spinning of the hollow fiber type IEMs was performed under the spinning conditions listed in Table 1.

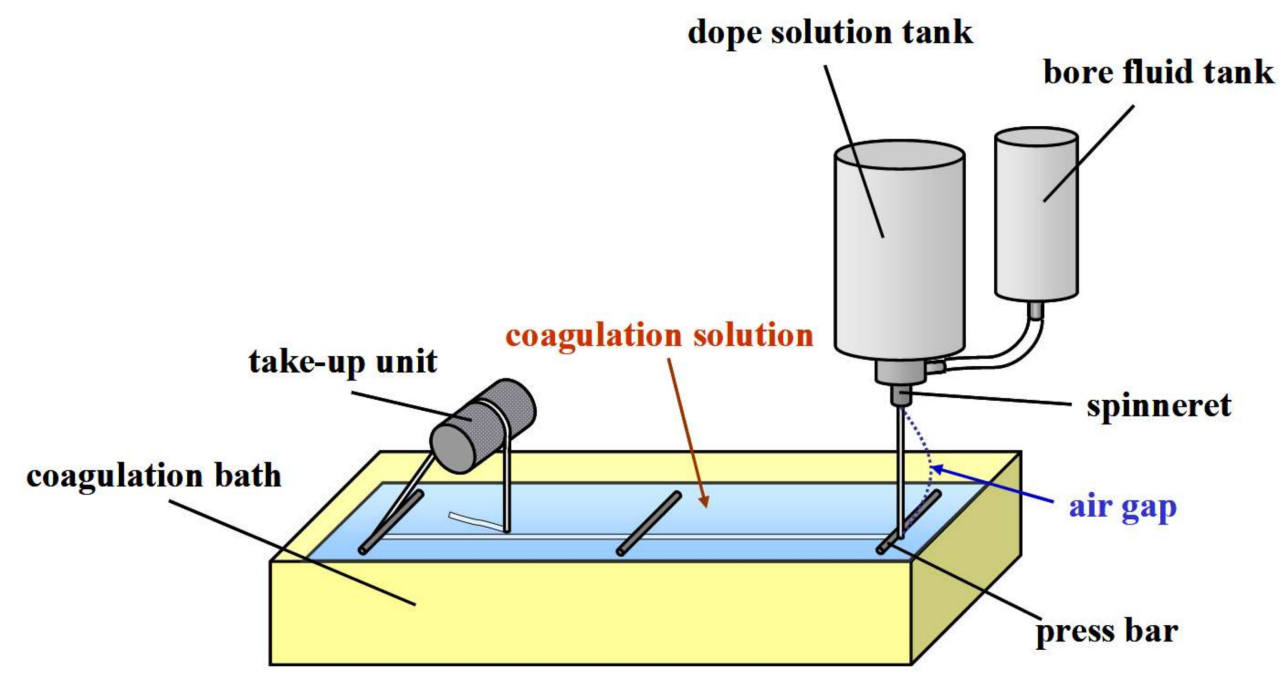

Figure 3. Schematic diagram of an apparatus of spinning hollow fiber type IEMs.

Table 1. Basic spinning conditions.

\begin{tabular}{ll}
\hline Dope solution & AP-2 and PVA/PDADMAC solution \\
Bore fluid & Water/Sodium hydrate/Sodium sulfate $(83 / 2 / 15, \mathrm{w} / \mathrm{w} / \mathrm{w})$ \\
External coagulant & Water/Sodium hydrate/Sodium sulfate $(83 / 2 / 15, \mathrm{w} / \mathrm{w} / \mathrm{w})$ \\
Spinneret dimensions $(\mathrm{mm})$ & $2.0 / 0.4$ (O.D./I.D.) \\
Dope solution temperature $\left({ }^{\circ} \mathrm{C}\right)$ & 90 \\
Bore fluid temperature $\left({ }^{\circ} \mathrm{C}\right)$ & 25 \\
External coagulant temperature $\left({ }^{\circ} \mathrm{C}\right)$ & 25 \\
Bore flow rate $(\mathrm{mL} / \mathrm{min})$ & 32 \\
Air gap $(\mathrm{cm})$ & 15 \\
\hline
\end{tabular}

After taking out the hollow fiber membranes from the coagulation bath, the membranes were immersed in a saturated aqueous sodium hydroxide solution of $\mathrm{pH} 1$ in order to remove boric acid. Afterward, in order to wash boric acid and acid adhering to the hollow fiber membranes, the membranes were immersed in a saturated sodium sulfate aqueous solution. 


\subsubsection{Cross-Linking Processes of the Hollow Fiber Type IEMs}

For physical cross-linking of the hollow fiber type IEMs (heat treatment), the prepared C-HF and A-HF membranes were immersed in ethanol to remove adhered salt. Afterward, the membranes were dried in an oven at $80{ }^{\circ} \mathrm{C}$ for $5 \mathrm{~h}$ under reduced pressure. In addition, heat treatment was performed at $160{ }^{\circ} \mathrm{C}$ for $10 \mathrm{~min}$. The membranes after the heat treatment were immersed in a saturated sodium sulfate aqueous solution.

For chemical cross-linking of the hollow fiber type IEMs (GA crosslinking), sulfuric acid was added to a predetermined amount of saturated sodium sulfate aqueous solution so as to be $\mathrm{pH} 1$. Then a predetermined amount of GA was added to prepare a GA solution. The hollow fiber type IEMs were immersed in the prepared GA solution at $25^{\circ} \mathrm{C}$ for $24 \mathrm{~h}$. The membranes subjected to GA crosslinking were immersed in deionized water for 1 week and were stored.

\subsection{Preparation of a Hollow Fiber Module}

Both ends of the fabricated hollow fiber type IEMs were fixed with epoxy resin, and the end of the epoxy resin parts was cut off to obtain a flow path. Two acrylic rods were incorporated to bridge the two resin parts so as to maintain the length of the membranes as a constant. A photograph of the module prepared was shown in Figure 4.

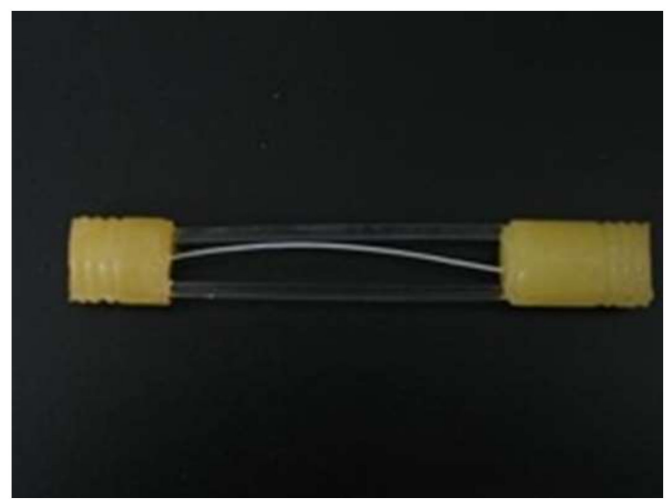

Figure 4. Photograph of a hollow fiber membrane module prepared in this study.

\subsection{Morphological Observation of Hollow Fiber Membranes}

After immersing a sample membrane in deionized water, the sample was fractured in liquid nitrogen and sputtered with gold using ion sputtering equipment (HITACHI E101 ION SPUTTER, Tokyo, Japan). The sample membrane was observed with a scanning electron microscope (SEM) (KEYENCE VE-8800, Osaka, Japan) to investigate the membrane morphology. The thickness, inside diameter, and outside diameter of the membrane were measured by a SEM image.

\subsection{Measurement of Mechanical Strength}

The mechanical strength of the prepared hollow fiber type IEMs was determined by measuring stress-strain curves using a table model-testing machine (SHIMAZU, EZ-Test500N, Kyoto, Japan). In the test, specimens with a nominal $3.5 \mathrm{~cm}$-gauge length were deformed by the test machine at a constant strain rate of $10 \mathrm{~mm} / \mathrm{min}$ at $25^{\circ} \mathrm{C}$. The stress-strain data were determined to fail.

\subsection{Measurement of Membrane Water Content}

The water content, $H$, was measured as follows. A base membrane was weighed in the dry state after the annealing treatment, and cross-linked chemically. The cross-linked membranes were immersed in deionized water at $25{ }^{\circ} \mathrm{C}$ for 7 days. The membranes were removed from the water, dabbed with filter paper to remove excess water on the membrane surfaces, and weighed in the wet 
state. The volumetric water content is calculated from the weights in the wet state, $W_{\mathrm{w}}$, and in the dry state, $W_{D}$, as:

$$
H=\frac{\left(W_{w}-W_{D}\right) / 1.0}{\left(W_{w}-W_{D}\right) / 1.0+\left(W_{D} / 1.3\right)}
$$

where 1.0 and $1.3 \mathrm{~g} / \mathrm{cm}^{3}$ are the densities of water and PVA, respectively.

\subsection{Measurement of Ion Exchange Capacity (IEC)}

IEC of an IEM is important because the ionic transport properties such as selectivity of ions depend on the amount and species of the ion exchange groups. IEC is expressed as milli-equivalent per gram of membrane (meq. $\mathrm{g}^{-1}$ dry IEM), and was determined as follows: A sample membrane was immersed in $0.10 \mathrm{M} \mathrm{KCl}$ solution for $3 \mathrm{~h}$ before measuring IEC to exchange the counter-ions of the fixed charged groups in the IEM with $\mathrm{K}^{+}$ions (C-HF membrane) or with $\mathrm{Cl}^{-}$ions (A-HF membrane), respectively. Then, the samples were immersed in $0.1 \mathrm{mM} \mathrm{KCl}$ solution to remove a droplet of $0.1 \mathrm{M}$ $\mathrm{KCl}$ solution on the membrane surfaces, and then immersed in $50 \mathrm{~mL}$ of $0.10 \mathrm{M} \mathrm{NaNO}_{3}$ for $12 \mathrm{~h}$ in order to obtain the complete exchange of $\mathrm{K}^{+}$ions in the membrane for $\mathrm{Na}^{+}$ions from the solution on the $\mathrm{C}$-HF membrane, and to obtain the complete exchange of $\mathrm{Cl}^{-}$ions in the membrane for $\mathrm{NO}_{3}{ }^{-}$ions from the solution on the A-HF membrane. The concentration of $\mathrm{K}^{+}$ions or $\mathrm{NO}_{3}{ }^{-}$ions obtained in the solution, $C_{i}$, was determined by using an ion chromatograph (Dionex ICS-1500, Sunnyvale, CA, USA). The membrane was dried under vacuum for $24 \mathrm{~h}$, and was weighed in the dry state, $W_{D}$. The IEC of the membranes was calculated using the following equation.

$$
I E C=\frac{C_{i}}{W_{D}} \times \frac{100}{1000}
$$

\subsection{Donnan Dialysis Experiment}

Ionic permeation experiments using an apparatus shown in Figure 5 were carried out using two types of the Donnan dialysis systems shown in Figure 6: mixed $0.1 \mathrm{M} \mathrm{NaCl}$ and $0.1 \mathrm{M} \mathrm{CaCl}_{2}$ (shell side) $/ \mathrm{C}-\mathrm{HF} / 3 \times 10^{-4} \mathrm{M} \mathrm{CaCl}_{2}$ (lumen side) and mixed $0.1 \mathrm{M} \mathrm{NaCl}$ and $0.1 \mathrm{M} \mathrm{NaNO}_{3}$ (shell side) / A-HF $/ 3 \times 10^{-4} \mathrm{MNaNO}_{3}$ (lumen side). The volume of the lumen and the shell solutions were $200 \mathrm{~cm}^{3}$ and $800 \mathrm{~cm}^{3}$, respectively. The solution in the lumen side was sampled to measure the concentration of $\mathrm{Na}^{+}$ions and $\mathrm{Ca}^{2+}$ ions with an ion chromatograph (DIONEX ICS-1500, Sunnyvale, CA, USA) in the case of the C-HF membrane, and that of $\mathrm{NO}_{3}{ }^{-}$ions and $\mathrm{Cl}^{-}$ions with an ion chromatograph (DIONEX ICS-2000, Sunnyvale, CA, USA) in the case of the A-HF membrane. The ionic flux of these ions, $J_{i}$, was obtained from the slope of their time-concentration curves in terms of the following equation.

$$
J_{i}=\frac{V}{S} \times \frac{\Delta C_{i}}{\Delta t}
$$

where, $V, S, \Delta C / \Delta t$ are the volume of the lumen side solution, the effective area of the sample membrane, and the initial slope of $i$ species ions, respectively. 


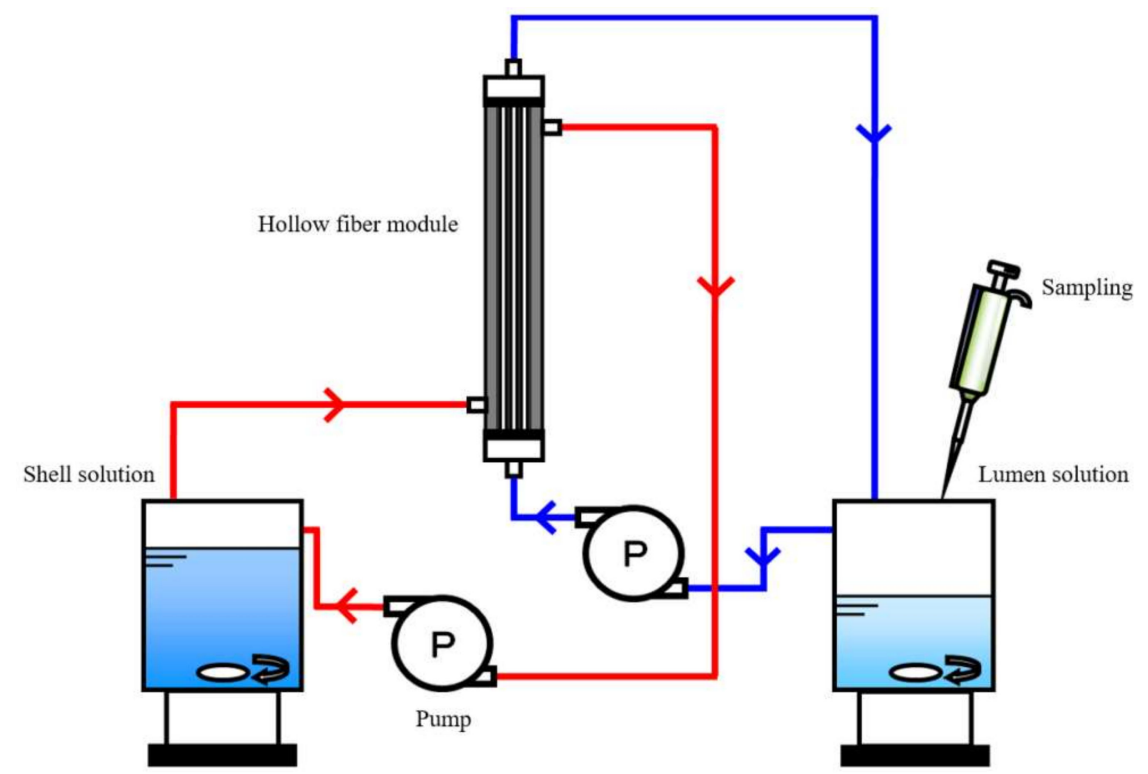

Figure 5. Schematic diagram of apparatus of Donnan dialysis experiments.

\begin{tabular}{|c|c|c|c|c|c|}
\hline $\begin{array}{l}\text { Shell side } \\
\mathrm{NaCl} \\
0.1 \mathrm{M} \\
\mathrm{CaCl}_{2}\end{array}$ & C-HF & $\begin{array}{l}\text { Lumen side } \\
\mathbf{C a C l}_{2} \\
\mathbf{3} \times \mathbf{1 0}^{-4} \mathbf{M}\end{array}$ & $\begin{array}{l}\text { Shell side } \\
\text { NaCl } \\
\mathbf{0 . 1}_{\mathrm{M}} \\
\mathrm{NaNO}_{3}\end{array}$ & A-HF & $\begin{array}{l}\text { Lumen side } \\
\mathrm{NaNO}_{3} \\
\mathbf{3} \times \mathbf{1 0}^{-4} \mathbf{M}\end{array}$ \\
\hline
\end{tabular}

Figure 6. Schematic diagram of Donnan dialysis systems using the C-HF membrane and the A-HF membrane.

\section{Results and Discussion}

\subsection{Morphology of the Hollow Fiber Type IEMs}

Figures 7 and 8 shows the SEM image of C-HF and A-HF membranes. A non-porous structure was shown from the cross-sectional image of SEM. The hollow fiber membranes were formed by dehydration and coagulation process, and by cross-linking with a hydrogen bond between boric acid and hydroxyl group of PVA. In addition, the physical cross-linking (annealing process) and the chemical cross-linking with GA were carried out to the membranes. Thus, the membrane matrix had a non-porous structure. The inner diameter (I.D.) and outer diameter (O.D.) and thickness of the membrane (d) determined by the cross-sectional image were listed in Table 2. The thickness of the C-HF membrane was almost equal to a commercial flat sheet CEM, Neosepta ${ }^{\circledR}$ CMX, whose thickness is $160 \mu \mathrm{m}$ and that of the A-HF membrane is about two times larger than that of a commercial flat sheet AEM, Neosepta ${ }^{\circledR}$ AMX, whose thickness is $170 \mu \mathrm{m}$. In the annealing process of the hollow fiber type IEMs, heat-drawing was not performed. The inner diameter and outer diameter (O.D.) and thickness of the membranes will decrease when the membranes are annealed with heat drawing. 

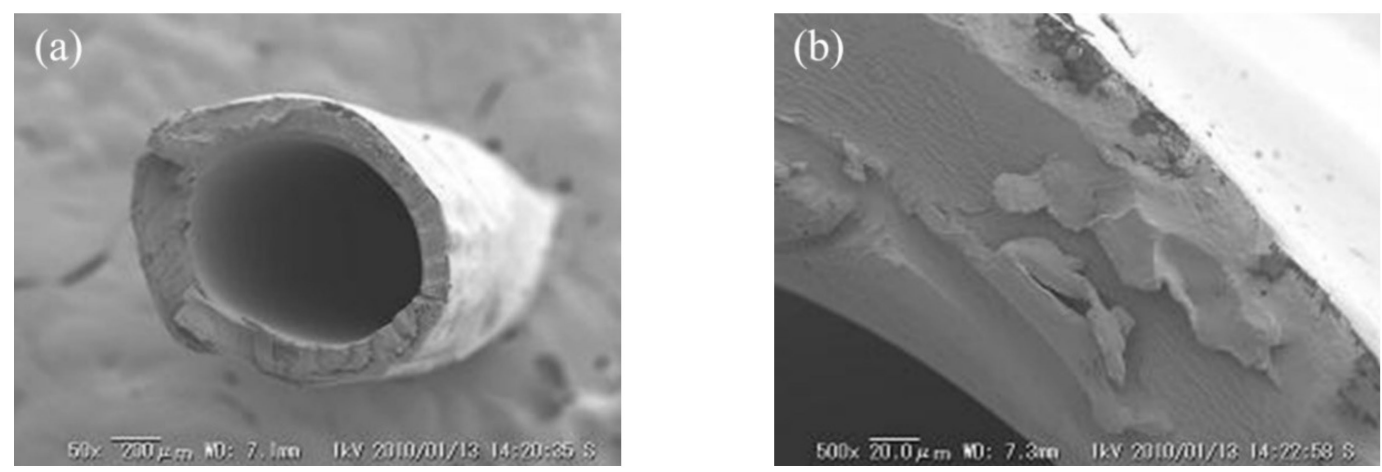

Figure 7. SEM cross-sectional image of C-HF membrane. (a) Overall membrane image and (b) close up image of the cross-section.
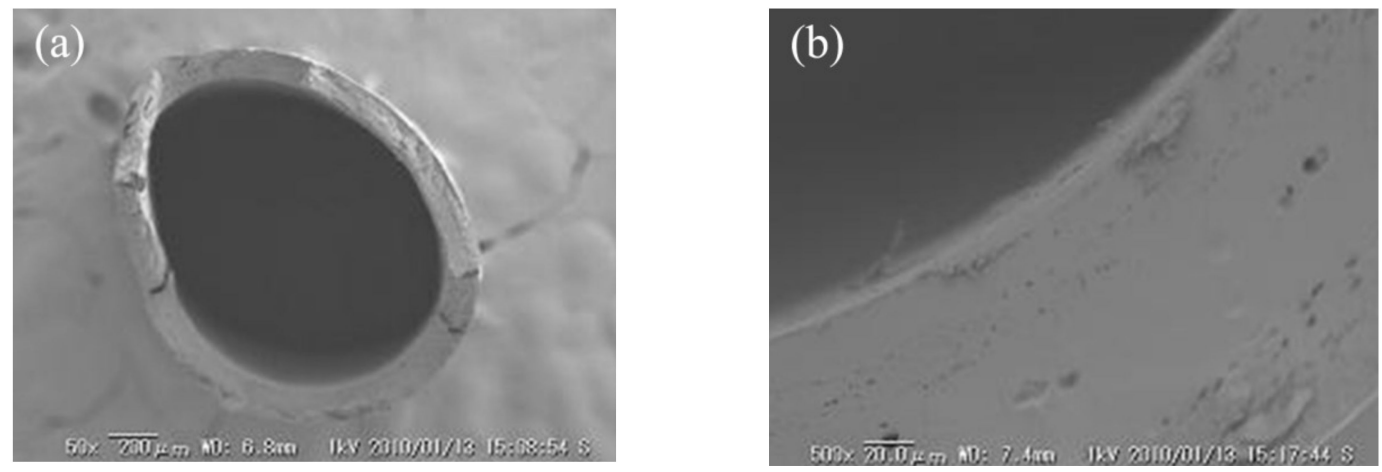

Figure 8. SEM cross-sectional image of the A-HF membrane. (a) Overall membrane image and (b) close up image of the cross-section.

Table 2. The diameters and thickness of the prepared hollow fiber type IEMs.

\begin{tabular}{cccc}
\hline Sample & I.D. $[\mu \mathrm{m}]$ & O.D. $[\mu \mathrm{m}]$ & $d[\mu \mathrm{m}]$ \\
\hline C-HF & 910 & 1080 & 170 \\
A-HF & 1210 & 1500 & 290 \\
\hline
\end{tabular}

\subsection{Water Content of the Membranes as a Function of GA Concentration}

Water content of an IEM is one of the several important properties because the membrane resistance, ionic selectivity, and mechanical strength of the membrane depends on the water content. Figures 9 and 10 show the water content of C-HF and A-HF membranes, respectively, as a function of GA concentration. The water content of the two hollw fiber type membranes decreased with an increasing GA concentration because the water content of an IEM decreases with an increase in the number of chemical cross-linking points [34]. In general, the ionic selectivity of an IEM increases while the permeability of ions decreases as the water content decreases. In addition, the mechanical strength decreases with increasing water content. Hence, the water content of C-HF and A-HF membranes should be controlled with changing GA concentration to optimize the membrane properties. 


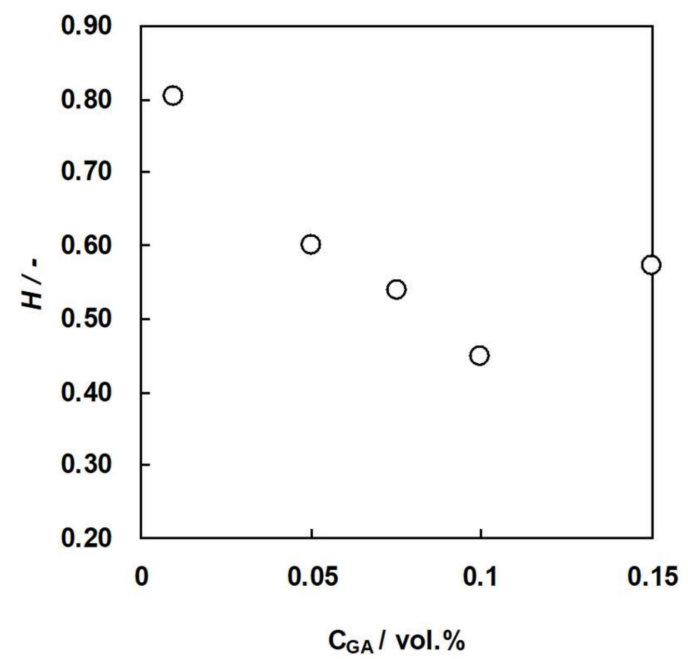

Figure 9. Water content, $H$, of $\mathrm{C}-\mathrm{HF}$ membranes as a function of GA concentration.

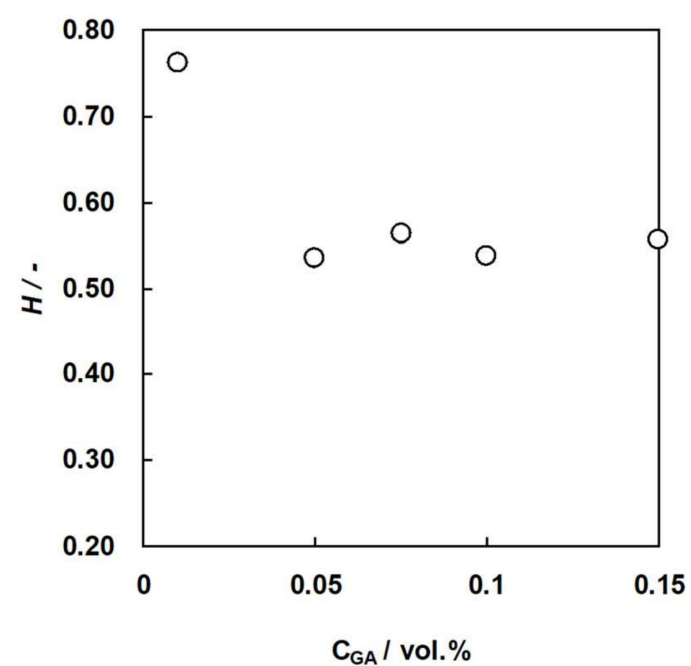

Figure 10. Water content, $H$, of A-HF membranes as a function of GA concentration.

\subsection{Mechanical Properties of the Membranes as a Function of GA Concentration}

Figure 11a shows the stress-strain curve of the C-HF membrane cross-linked with various GA concentrations. Figure $11 \mathrm{~b}$ shows Young's modulus of the membranes calculated from the slope of the stress-strain curve as a function of GA concentration. As expected, the maximum tensile strength at break and the Young's modules increased with increasing GA concentration, and the membrane cross-linked with $0.15 \mathrm{wt} \%$ GA showed $15 \mathrm{MPa}$ and $23 \mathrm{MPa}$ of the tensile strength and Young's modules, respectively. Figure 12a shows the stress-strain curve of A-HF membranes cross-linked with various GA concentrations, and Figure 12b shows Young's modulus of the membranes. The mechanical properties of A-HF membranes have the same tendency as those of C-HF membranes, which shows that the mechanical strength increased with increasing GA concentration, and the membranes with $0.15 \mathrm{wt} \%$ of GA showed 3.5 MPa of the tensile strength at break and $24 \mathrm{MPa}$ of Young's modules. Both C-HF and A-HF membranes were annealed at $160^{\circ} \mathrm{C}$ for physical cross-linking. M. Higa et al. reported that the degree of crystallinity of PVA-based CEMs prepared from AP-2 polymer increased with increasing annealing temperature, and the membrane annealed at $190{ }^{\circ} \mathrm{C}$ showed the higher degree of crystallinity and also had higher tensile strength and Young's modulus than those of CEMs annealed at lower temperatures [35]. Hence, hollow fiber type IEMs annealed at more than $190{ }^{\circ} \mathrm{C}$ will have higher mechanical strength than those in the study annealed at $160^{\circ} \mathrm{C}$. 


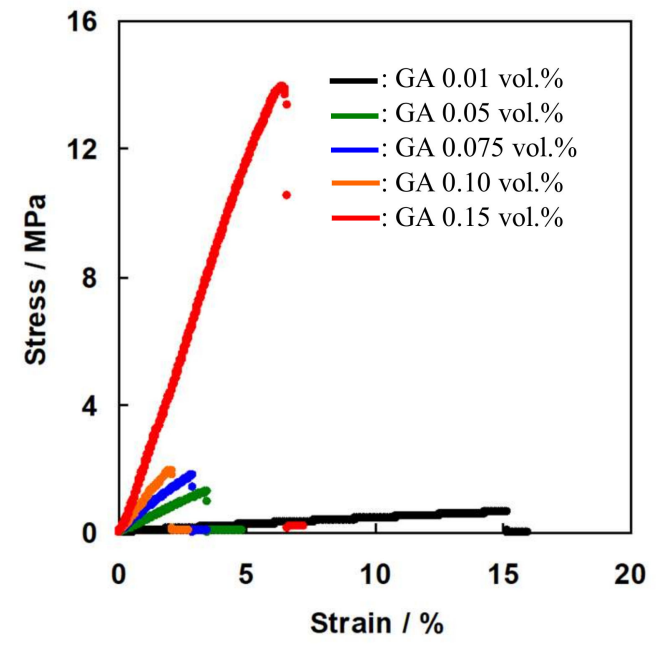

(a)

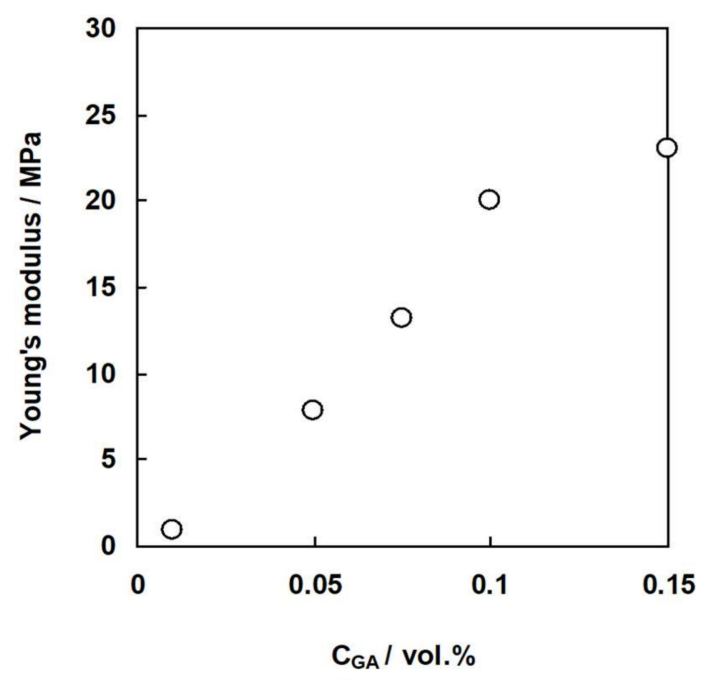

(b)

Figure 11. (a) Stress-strain curve of C-HF membranes. (b) Young's modulus of C-HF membranes as a function of GA concentration.

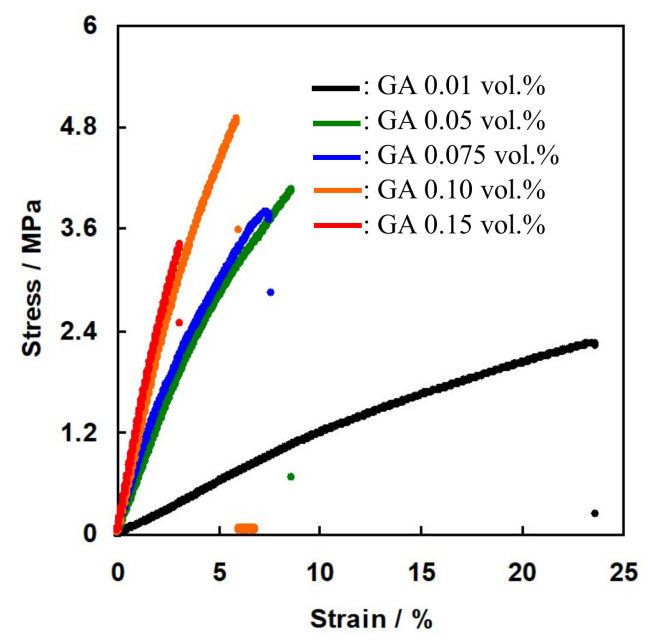

(a)

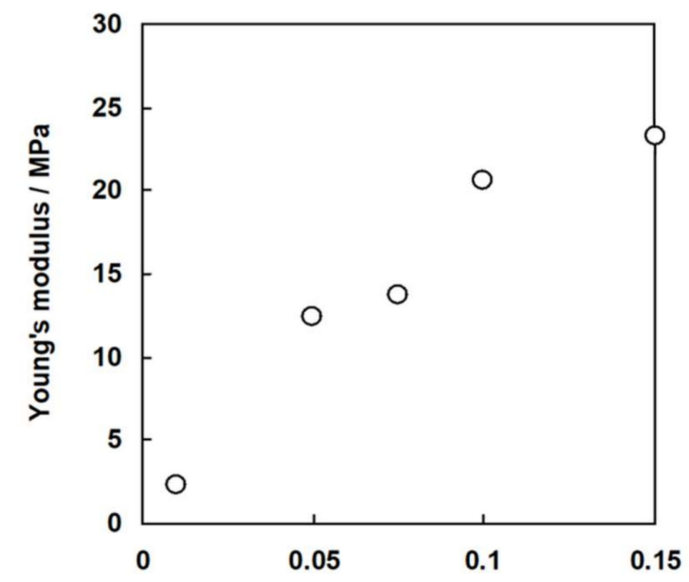

(b)

Figure 12. (a) Stress-strain curve of A-HF membranes. (b) Young's modulus of A-HF membranes as a function of GA concentration.

\subsection{Ion-Exchange Capacity of the Hollow Fiber Type Ion-Exchange Membranes}

Table 3 shows theoretical ion-exchange capacity (IEC) and measured IEC of C-HF and A-HF membranes as well as the measured IEC of CMX and AMX as a reference. The measured IEC of both $\mathrm{C}-\mathrm{HF}$ and A-HF membranes were lower than the theoretical one. The reasons for the lower value in the measured IEC can be considered as follows: In the case of C-HF membranes, the molar percent is the average value, and the AP-2 polymer chains with higher molar percent than the average percent may dissolve out easier than those with lower molar percent during the spinning process because the former has higher water solubility than the latter. In the case of A-HF membranes, the linear chains of PDADMAC may dissolve out during the spinning process. IEC of both C-HF and A-HF membranes were lower than commercial IEMs: about one fifth of CMX, and about a half of AMX, respectively. 
Table 3. Ion exchange capacities of the hollow fiber type IEMs and the commercial IEMs.

\begin{tabular}{ccc}
\hline Sample & Theoretical IEC (meq/g) & Measured IEC (meq/g) \\
\hline CMX & - & 1.50 \\
AMX & - & 1.40 \\
C-HF & 0.42 & 0.28 \\
A-HF & 1.25 & 0.61 \\
\hline
\end{tabular}

\subsection{Donnan Dialysis of C-HF Membranes}

Figures 13 and 14 show flux of $\mathrm{Ca}^{2+}$ ions and $\mathrm{Na}^{+}$ions and the selectivity coefficient between the ions through C-HF membranes as a function of GA concentration where $\mathrm{Ca}^{2+}$ ions and $\mathrm{Na}^{+}$ions are the uphill transported ions and the driving ions, respectively. Here, the flux of $\mathrm{Na}^{+}$ions is defined as a positive value when the movement of the ions from the shell to the lumen sides occurs, and the flux of $\mathrm{Ca}^{2+}$ ions is defined as a positive value when the movement from the lumen to the shell sides occurs. Hence, $\mathrm{Ca}^{2+}$ ions were transported against their concentration gradient (Uphill transport), and were driven by the diffusion of $\mathrm{Na}^{+}$ions. Therefore, the concentration of $\mathrm{Ca}^{2+}$ ions at the lumen side decreased while the concentration at the shell side increased. The flux of $\mathrm{Na}^{+}$ions as the driven ions decreased showed increased GA concentration because the water content of the membranes decreased with increasing GA concentration, as shown in Figure 9. The flux of $\mathrm{Na}^{+}$ions and $\mathrm{Ca}^{2+}$ ions through CMX under the same experimental conditions, as shown in the solid and broken lines, were 8.0 and $6.0 \times 10^{-6} \mathrm{~mol} \cdot \mathrm{m}^{-2} \cdot \mathrm{s}^{-1}$, respectively, which indicates that C-HF membranes had slightly smaller flux of $\mathrm{Ca}^{2+}$ ions than CMX. In the Donnan dialysis system using C-HF membranes, the following equation should be given based on Equation (1).

$$
J_{\mathrm{Na}}+2 J_{\mathrm{Ca}}-J_{\mathrm{Cl}}=0
$$

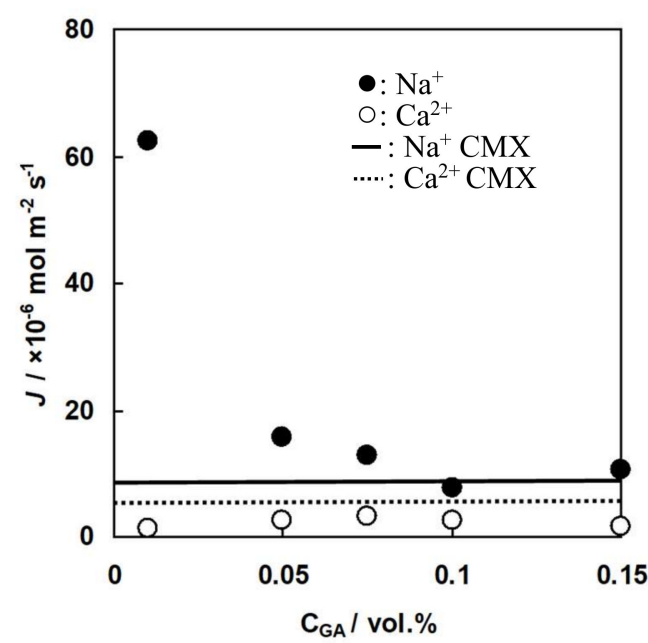

Figure 13. Flux of cations through C-HF membranes, $J$, as a function of GA concentration. Flux through C-HF membranes: solid circles, $\mathrm{Na}^{+}$ions; open ones, $\mathrm{Ca}^{2+}$ ions. Flux through $\mathrm{CMX}$ : solid line, $\mathrm{Na}^{+}$ions, dotted one, $\mathrm{Ca}^{2+}$ ions.

The selectivity coefficient of CMX shown as the solid line in Figure 14 was 0.98 . Hence, CMX has almost perfect cation selectivity. In the case of C-HF membranes, both the flux of $\mathrm{Ca}^{2+}$ ions and the selectivity coefficient increased with increasing GA concentration, accepting the membrane with $0.15 \%$ GA concentration. This is due to the fact that the charge density of the membrane, which is defined as the division of IEC by the water content, will increase with increasing GA concentration because of the decrease in the water content of C-HF membranes. In general, the higher charge density of an ion-exchange membrane has a higher selectivity for counter-ions. Therefore, the selectivity coefficient 
of C-HF membranes increased with increasing GA concentration. C-HF membrane with 0.15 vol.\% of GA concentration showed a lower selectivity coefficient and a higher flux of $\mathrm{Na}^{+}$ions than the membrane with $0.10 \mathrm{vol} . \%$ of GA concentration. The reason why C-HF membrane with $0.15 \mathrm{vol} . \%$ had a low selectivity coefficient may be that there were some small cracks in the membrane because it had a high Young's modulus and was brittle.

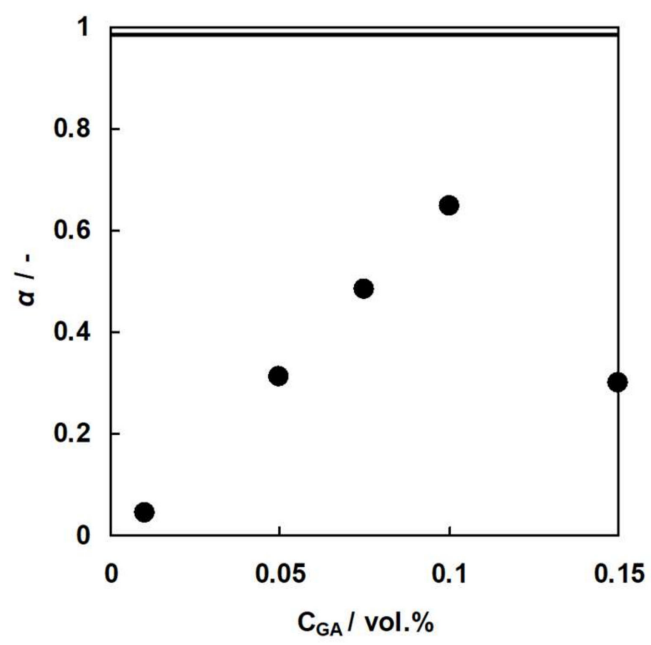

Figure 14. The selectivity coefficient, $\alpha$, of C-HF membranes as a function of GA concentration. Solid circles, C-HF membranes. Solid line, CMX.

\subsection{Donnan Dialysis of A-HF Membranes}

Figures 15 and 16 show the flux of $\mathrm{Cl}^{-}$ions and $\mathrm{NO}_{3}{ }^{-}$ions, and the selectivity coefficient between the ions through A-HF membranes is a function of GA concentration where $\mathrm{NO}_{3}{ }^{-}$ions and $\mathrm{Cl}^{-}$ ions are the uphill transported ions and the driving ions, respectively. Figure 15 indicates that uphill transport of $\mathrm{NO}_{3}{ }^{-}$ions occurred, which was driven by the diffusion of $\mathrm{Cl}^{-}$ions. The flux of $\mathrm{Cl}^{-}$ions decreased with increasing GA concentration because the water content of the membranes decreased with increasing GA concentration, as shown in Figure 10. The flux of $\mathrm{Cl}^{-}$ions and $\mathrm{NO}_{3}{ }^{-}$ions through AMX shown as the solid and broken lines were 9.0 and $8.7 \times 10^{-6} \mathrm{~mol} \cdot \mathrm{m}^{-2} \cdot \mathrm{s}^{-1}$, respectively. Hence, the flux of $\mathrm{NO}_{3}{ }^{-}$ions through A-HF membranes is about half of that of AMX because A-HF membranes had a larger membrane thickness $(290 \mu \mathrm{m})$ than that of AMX $(170 \mu \mathrm{m})$. In the Donnan dialysis system using A-HF membranes, the following equation is derived from Equation (1).

$$
J_{\mathrm{Na}}-J_{\mathrm{Cl}}-J_{\mathrm{NO} 3}=0
$$

The solid line in Figure 16 indicates that the selectivity coefficient of AMX was 0.98. Hence, AMX has almost perfect anion selectivity. In the case of A-HF membranes, the selectivity coefficient increased with increasing GA concentration. This will be due to the fact that the charge density of the membrane will increase with increasing GA concentration because of the decrease in the water content of A-HF membranes. The selectivity coefficient of A-HF membranes was less than half of that of AMX even though the selectivity coefficient of C-HF membranes was higher than half of CMX. The difference in the selectivity coefficient between C-HF and A-HF membranes can be explained as follows: distribution of divalent counter-ions inside an ion-exchange membrane is higher than that of monovalent counter-ion based on the Donnan equilibrium [36]. Hence, the selectivity coefficient of C-HF membrane for $\mathrm{Ca}^{2+}$ ions was higher than that of the A-HF membrane for $\mathrm{NO}_{3}{ }^{-}$ions even though the former membrane has lower IEC than the latter one. 


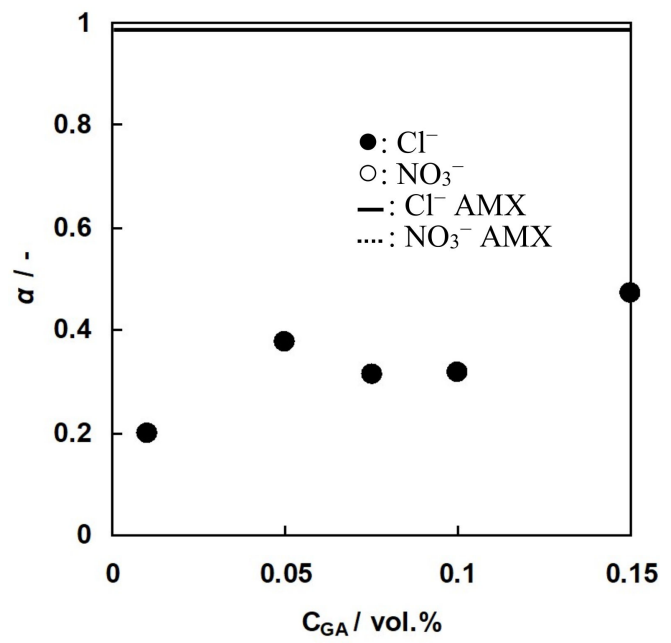

Figure 15. Flux of anions through A-HF membranes, $J$, of A-HF membranes as a function of GA concentration. Flux through A-HF membranes: solid circles, $\mathrm{Cl}^{-}$ions. Open ones, $\mathrm{NO}_{3}{ }^{-}$ions. Flux through AMX: solid line, $\mathrm{Cl}^{-}$ions. Dotted one, $\mathrm{NO}_{3}{ }^{-}$ions.

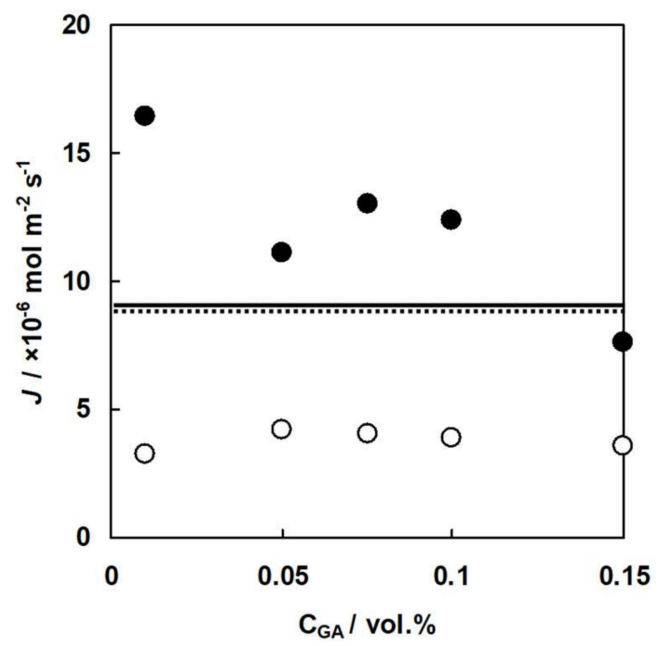

Figure 16. Selectivity coefficient, $\alpha$, of A-HF membranes as a function of GA concentration. Solid circles, A-HF membranes. Solid line, AMX.

The hollow fiber type IEMs, C-HF and A-HF membranes, prepared in this study had about half of the flux in the uphill transported ions and also about half of the selectivity coefficient between the uphill transport ions and driven ions when compared with the commercial flat sheet IEMs. Flat sheet cation-exchange membranes prepared from AP-2 had higher performance at high annealing temperatures [35]. Moreover, Flat sheet CEMs prepared from PVA-based block copolymer, poly(vinyl alcohol-b-styrene sulfonic acid) had higher performance for CEMs than that from PVA-based random copolymer, AP-2 [37]. Hence, PVA-based hollow fiber type IEMs prepared from the block copolymer annealed at high temperatures will show higher performance than the IEMs in this study. Moreover, as mentioned above, in the annealing process of the hollow fiber type IEMs, heat-drawing was not performed. Sadao et al. reported that the degree of crystallinity in a PVA film will increase as the crystalline orientation of a PVA film increases in a heat-drawing process [38]. Hence, a PVA-based hollow fiber type IEM with a high heat-drawing ratio will have higher performance in Donnan dialysis because of its higher degree of crystallinity and thinner membrane thickness. 


\section{Conclusions}

In this study, we prepared hollow fiber type cation-exchange (C-HF) membranes and anion-exchange (A-HF) membranes from PVA-based copolymer with cation-exchange groups and from a mixture of PVA and polycation, respectively, using the gel spinning method. The fundamental properties of the prepared membranes were measured. We also performed Donnan dialysis measurements to examine the perm selectivity of the membranes.

The water content of the membranes increased with increasing cross-linker (GA) concentration at the chemical cross-linking process. IEC of C-HF and A-HF membranes were about one-fifth of that of CMX, and about one-half of that of AMX, respectively.

In the Donnan dialysis experiments using C-HF membranes, uphill transport of the divalent cations occurred. Hence, the concentration at the lumen side decreased and the cations were concentrated to the shell side, which has high concentration of the driving ions. In the experiments using A-HF membranes, uphill transport of $\mathrm{NO}_{3}{ }^{-}$ions occurred. The hollow fiber type IEMs, $\mathrm{C}-\mathrm{HF}$ and A-HF membranes, had about half of the flux in the uphill transported ions and also about half of the selectivity between the uphill transport ions and driven ions in comparison with commercial flat sheet IEMs.

A membrane module using hollow fiber type IEMs will have higher packing density than a plate-and-frame stack using flat sheet IEMs. In addition, PVA-based hollow fiber type IEMs with heat-drawing will have higher performance in the Donnan dialysis process than the IEMs prepared in this study. Therefore, PVA-based hollow fiber type IEMs will have a potential application in the Donnan dialysis processes.

Author Contributions: Conceptualization and supervision, M.H.; experiments and analysis, T.S., K.T. and Y.K.; writing-original draft preparation, T.S. and Y.K.; writing-review and editing, M.H.; funding acquisition, M.H and Y.K.

Funding: This work was partly supported by JSPS KAKENHI Grant Number 16H01796, and by the Salt Science Research Foundation Grant No.1504.

Conflicts of Interest: The authors declare no conflict of interest.

\section{References}

1. Sata, T. Ion Exchange Membranes: Preparation, Characterizaion, Modification and Application; Royal Society of Chemistry: London, UK, 2004; ISBN 0854045902.

2. $\mathrm{Xu}, \mathrm{T}$. Ion exchange membranes: State of their development and perspective. J. Membr. Sci. 2005, 263, 1-29. [CrossRef]

3. Tanaka, Y. Ion Exchange Membranes Fundamentals and Applications, 2nd ed.; Elsevier: Amsterdam, The Netherlands, 2015; ISBN 9780444633194.

4. Strathmann, H. Electrodialysis, a mature technology with a multitude of new applications. Desalination 2010, 264, 268-288. [CrossRef]

5. Campione, A.; Gurreri, L.; Ciofalo, M.; Micale, G.; Tamburini, A.; Cipollina, A. Electrodialysis for water desalination: A critical assessment of recent developments on process fundamentals, models and applications. Desalination 2018, 434, 121-160. [CrossRef]

6. Narebska, A.; Warszawski, A. Diffusion dialysis. Effect of membrane composition on acid/salt separation. Sep. Sci. Technol. 1992, 27, 703-715. [CrossRef]

7. Luo, J.; Wu, C.; Xu, T.; Wu, Y. Diffusion dialysis-concept, principle and applications. J. Membr. Sci. 2011, 366, 1-16. [CrossRef]

8. Yamabe, T. Present status of electrodialysis in Japan. Desalination 1977, 23, 195-202. [CrossRef]

9. Š́mová, H.; Kysela, V.; Černín, A. Demineralization of natural sweet whey by electrodialysis at pilot-plant scale. Desalin. Water Treat. 2010, 14, 170-173. [CrossRef]

10. Andres, L.J.; Riera, F.A.; Alvarez, R. Recovery and concentration by electrodialysis of tartaric acid from fruit Juice industries waste waters. J. Chem. Technol. Biotechnol. 1997, 70, 247-252. [CrossRef] 
11. Acheampong, M.A.; Meulepas, R.J.W.; Lens, P.N.L. Removal of heavy metals and cyanide from gold mine wastewater. J. Chem. Technol. Biotechnol. 2010, 85, 590-613. [CrossRef]

12. Herz, G.P.; Byszewski, C.; Jaffari, M. Recovery of Acids and Bases Used in Metal Treatment Processes by Diffusion Dialysis; Hydrometallurgy '94; Chapman \& Hail: London, UK, 1994; pp. 613-626.

13. Szczepański, P.; Szczepańska, G. Donnan dialysis-A new predictive model for non-steady state transport. J. Membr. Sci. 2017, 525, 277-289. [CrossRef]

14. Akretche, D.E.; Kerdjoudj, H. Donnan dialysis of copper, gold and silver cyanides with various anion exchange membranes. Talanta 2000, 51, 281-289. [CrossRef]

15. Hamouda, S.B.; Touati, K.; Amor, M.B. Donnan dialysis as membrane process for nitrate removal from drinking water: Membrane structure effect. Arab. J. Chem. 2017, 10, S287-S292. [CrossRef]

16. Kiyono, R.; Koops, G.H.; Wessling, M.; Strathmann, H. Mixed matrix microporous hollow fibers with ion-exchange functionality. J. Membr. Sci. 2004, 231, 109-115. [CrossRef]

17. Barzin, J.; Madaeni, S.S.; Pourmoghadasi, S. Hemodialysis membranes prepared from poly(vinylalcohol): Effects of the preparation conditions on the morphology and performance. J. Appl. Polym. Sci. 2007, 104, 2490-2497. [CrossRef]

18. Su, B.H.; Fu, P.; Li, Q.; Tao, Y.; Li, Z.; Zao, H.S.; Zhao, C.H. Evaluation of polyethersulfone highflux hemodialysis membrane in vitro and in vivo. J. Mater. Sci. Mater. Med. 2008, 19, 745-751. [CrossRef] [PubMed]

19. Fu, X.; Matsuyama, H.; Teramoto, M.; Nagai, H. Preparation of polymer blend hollow fiber membrane via thermally induced phase separation. Sep. Purif. Technol. 2006, 52, 363-371. [CrossRef]

20. Fujiwara, N.; Matsuyama, H. The analysis and design of a both open ended hollow fiber type RO module. J. Appl. Polym. Sci. 2008, 110, 2267-2277. [CrossRef]

21. Tchobanoglous, G.; Darby, J.; Bourgeous, K.; McArdle, J.; Genest, P.; Tylla, M. Ultrafiltration as an advanced tertiary treatment process for municipal wastewater. Desalination 1998, 119, 315-322. [CrossRef]

22. Saito, K.; Saito, K.; Sugita, K.; Tamada, M.; Sugo, T. Cation-exchange porous hollow-fiber membranes prepared by radiation-induced cografting of GMA and EDMA which improved pure water permeability and sodium ion adsorptivity. Ind. Eng. Chem. Res. 2002, 41, 5686-5691. [CrossRef]

23. Shirataki, H.; Sudoh, C.; Eshima, T.; Yokoyama, Y.; Okuyama, K. Evaluation of an anion-exchange hollow-fiber membrane adsorber containing-ray grafted glycidyl methacrylate chains. J. Chromatogr. A 2011, 1218, 2381-2388. [CrossRef]

24. Wang, N.; Cui, M.; Wu, C.; Cheng, Y.; Xu, T. Hybrid Anion Exchange Hollow Fiber Membrane for Delivery of Ionic Drugs. Int. J. Chem. Eng. 2012, 2012, 832190. [CrossRef]

25. Lebrum, L.; Follain, N.; Metayer, M. Elaboration of a new anion-exchange membrane with semi-interpenetrating polymer networks and characterization. Electrochim. Acta 2004, 50, 985-993. [CrossRef]

26. M'Bareck, C.O.; Metayer, M.; Nguyen, Q.T.; Alexandre, S.; Malandain, J.J. Microporous anion-exchange membranes made of semi-interpenetrating polymer network I. Elaboration and characterization. J. Membr. Sci. 2003, 221, 53-68. [CrossRef]

27. Choi, Y.J.; Park, J.M.; Yeon, K.H.; Moon, S.H. Electrochemical characterization of poly(vinyl alcohol)/formyl methyl pyridinium (PVA-FP) anion-exchange membranes. J. Membr. Sci. 2005, 250, 295-304. [CrossRef]

28. Jikihara, A.; Ohashi, R.; Kakihana, Y.; Higa, M.; Kobayashi, K. Electrodialytic transport properties of anion-exchange membranes prepared from poly(vinyl alcohol) and poly(vinyl alcohol-co-methacryloyl aminopropyl trimethyl ammonium chloride). Membranes 2013, 3, 1-15. [CrossRef] [PubMed]

29. Hickey, A.S.; Peppas, N.A. Mesh size and diffusive characteristics of semicrystalline poly(vinyl alcohol) membranes prepared by freezing/thawing techniques. J. Membr. Sci. 1995, 107, 229-237. [CrossRef]

30. Hasimi, A.; Stavropoulou, A.; Papadokostaki, K.G.; Sanopoulou, M. Transport of water in polyvinyl alcohol films: Effect of thermal treatment and chemical crosslinking. Eur. Polym. J. 2008, 44, 4098-4107. [CrossRef]

31. Qin, X.H.; Wang, S.Y. Filtration Properties of Electrospinning Nanofibers. J. Appl. Polym. Sci. 2006, 10, 1285-1290. [CrossRef]

32. Higa, M.; Feng, S.; Endo, N.; Kakihana, Y. Characteristics and direct methanol fuel cell performance of polymer electrolyte membranes prepared from poly(vinyl alcohol-b-styrene sulfonic acid). Electrochim. Acta 2015, 153, 83-89. [CrossRef]

33. Higa, M.; Toyota, K.; Sugimoto, T. Characterization of hydrophilic hollow fiber membranes prepared from poly(vinyl alcohol). Desalin. Water Treat. 2010, 17, 199-203. [CrossRef] 
34. Tanaka, N.; Nagase, M.; Higa, M. Preparation of aliphatic-hydrocarbon-based anion-exchange membranes and their anti-organic-fouling properties. J. Membr. Sci. 2011, 384, 27-36. [CrossRef]

35. Higa, M.; Hatemura, K.; Sugita, M.; Maesowa, S.; Nishimura, M.; Endo, N. Performance of passive direct methanol fuel cell with poly(vinyl alcohol)-based polymer electrolyte membranes. Int. J. Hydrogen Energy 2012, 37, 6292-6301. [CrossRef]

36. Higa, M.; Tanioka, A.; Miyasaka, K. Simulation of the Transport of ions against their concentration gradient across charged membranes. J. Membr. Sci. 1988, 37, 251-266. [CrossRef]

37. Higa, M.; Nishimura, M.; Kinoshita, K.; Jikihara, A. Characterization of cation-exchange membranes prepared from poly(vinyl alcohol) and poly(vinyl alcohol-b-styrene sulfonic acid). Int. J. Hydrogen Energy 2012, 37, 6161-6168. [CrossRef]

38. Hibi, S.; Suzuki, K.; Hirano, T.; Torii, T.; Fujita, K.; Nakanishi, E.; Maeda, M. Orientation distribution function in crystallites of rolled polypropylene and poly(vinyl alcohol) films. Kobunshi Ronbunshu 1988, 45, 237-244. [CrossRef]

(C) 2019 by the authors. Licensee MDPI, Basel, Switzerland. This article is an open access article distributed under the terms and conditions of the Creative Commons Attribution (CC BY) license (http://creativecommons.org/licenses/by/4.0/). 